1 Winzenberg T, Shaw K, Fryer J, Jones G. Effects of calcium supplementation on bone density in healthy children: meta-analysis of randomised tion on bone density in healthy children: meta-analysis of rand

2 Lloyd T, Beck TJ, Lin HM, Tulchinsky M, Eggli DF, Oreskovic TL, et al. Modifiable determinants of bone status in young women. Bone 2002;30:416-21.

3 Bachrach LK. Acquisition of optimal bone mass in childhood and adolescence. Trends Endocrinol 2001;12:22-8.

4 Wosje KS, Specker BL. Role of calcium in bone health during childhood. Nutr Rev 2000;58:253-68.

5 Lanou AJ, Berkow SE, Barnard ND. Calcium, dairy products and bone health in children and young adults: a re-evaluation of the evidence. Pediatrics 2005; 115:736-43.

6 Report of a Joint Food and Agriculture Organization of the United Nations/World Food Organization of the United Nations Expert Consultation. Human vitamin and mineral requirements. Bangkok, Thailand;
September 1998. ftp://ftp.fao.org/es/esn/nutrition/Vitrni/vitrni.html (last accessed 6 Oct 2006).

7 Abelow BJ, Holford TR, Insogna KL. Cross-cultural association between dietary animal protein and hip fracture: a hypothesis. Calcif Tissue Int 1992;50:14-8

8 Subar AF, Krebs-Smith SM, Cook A, Kahle LL. Dietary sources of nutrient among US children, 1989-1991. Pediatrics 1998;102:913-23.

9 Larsson SC, Bergkvist L, Wolk A. Milk and lactose intakes and ovarian cancer risk in the Swedish mammography cohort. Am J Clin Nutr 2004:80:1353-7.

10 Chan JM, Stampfer MJ, Ma J, Gann PH, Gaziano JM, Giovannucci E. Dairy products, calcium, and prostate cancer risk in the physicians' health study. Am J Clin Nutr 2001;74:549-54.

doi $10.1136 /$ bmj.38996.499410.BE

\title{
Prevention of diabetes
}

\section{Drug trials show promising results, but have limitations}

$\mathrm{D}$ iabetes affects one in 20 adults worldwide and 333 million cases are projected worldwide by 2025. ${ }^{1}$ Treatment can prevent some of the microvascular and macrovascular complications, but diagnosis is often delayed until complications present, ${ }^{2}$ so attention has focused on prevention and early screening. Two strategies currently exist for reducing the onset of diabetes-lifestyle interventions and drugs.

The Diabetes Prevention Program Research Group study found that lifestyle interventions delivered over 2.8 years reduced the incidence of diabetes by $58 \%{ }^{3} \mathrm{~A}$ similar reduction in risk was found in a Finnish study of 522 people at risk. ${ }^{4}$ The problem is that these interventions are labour intensive-one study needed 16 one to one sessions delivered by case managers to achieve target weight reduction and exercise levels. ${ }^{3}$ Although lifestyle interventions produce successful results in research settings, they are difficult to replicate even in well funded healthcare systems.

Considerable interest has focused on the prevention of diabetes with drugs. For instance, the Diabetes Prevention Program Research Group study found a $31 \%$ reduction in the incidence of diabetes with metformin at 2.8 years. ${ }^{3}$ Previously troglitazone was shown to be effective in controlling blood sugar levels but was removed from the market because of serious liver toxicity. ${ }^{5}$ In people with obesity orlistat has been shown to reduce the risk of diabetes by $37 \%$ when compared with placebo. ${ }^{6}$

More recently came the publication of the diabetes reduction assessment with ramipril and rosiglitazone medication (DREAM) trial. $^{78}$ In this trial, which cost $\$ 25 \mathrm{~m}$ (£13m; €20m), 5269 people over 30 years with impaired fasting glucose or impaired glucose tolerance, or both, and no previous cardiovascular disease were randomised to receive either rosiglitazone $8 \mathrm{mg}$ daily or placebo, or ramipril $15 \mathrm{mg}$ daily or placebo. The primary outcome was a composite of incidence of diabetes or death over a three year median follow-up period.

The trial was well executed; randomisation produced equivalent groups via a concealed computer telephone group. Although the drop out rate was high at around $25 \%$, the analysis was on an intention to treat basis. At the end of the study $306(11.6 \%)$ of the patients taking rosiglitazone developed diabetes compared with 686 $(26 \%)$ of those given placebo (hazard ratio $0.40,95 \%$ confidence interval 0.35 to $0.46, \mathrm{P}<0.0001)$. Ramipril did not reduce the risk of diabetes.

These results are promising, but they should be interpreted with caution. The mean fasting plasma concentration of glucose in both groups at baseline was $5.8 \mathrm{mmol} / \mathrm{l}$, whereas the two hour impaired glucose tolerance test had a value of $8.7 \mathrm{mmol} / \mathrm{l}$. The study population was therefore composed predominantly of people with impaired glucose tolerance rather than those with abnormal fasting glucose. Fasting glucose concentrations rather than impaired glucose tolerance are usually used to screen for diabetes in the United Kingdom. Secondly, the rationale for using a composite end point of death and diabetes is unclear. Several considerations should be taken into account when using a composite end point. ${ }^{9}$ These include whether the component outcomes carry similar weight of importance to patients; and whether the component outcomes are likely to have similar relative risk reductions. This is not the case for death rates, which were similar in both groups and therefore should be analysed separately. Furthermore, despite the population being at low risk of heart failure (10 year risk $0.33 \%$ ) a significant increase $(0.4 \%)$ in heart failure was seen in the rosiglitazone group compared with placebo $(7.03,1.60$ to 30.9 , number needed to harm at three years 250). The use of thiazolidinediones is increasingly recognised as being associated with fluid retention and heart failure, and this is more common when they are combined with insulin. ${ }^{5}$ Also the drug showed no clear benefit on patient relevant outcomes at three years - the rate of all cardiovascular events was higher in the intervention group (1.37, 0.97 to 1.94 , $\mathrm{P}=0.08$ ).

A key question that remains is whether rosiglitazone prevents the onset of type II diabetes or merely lowers blood sugar concentrations in patients with new onset diabetes. As in the metformin trial in 2002, this can only be resolved by analysis after a washout period, which is promised later in the year.

The finding that rosiglitazone can prevent diabetes in people at risk of getting diabetes needs to be tempered with possible adverse effects of the drug, such as heart failure, and perhaps the risk of medicalising a lifestyle issue. Providing drugs is expensive, even without the additional costs of monitoring their side effects and treating them. Lifestyle interventions seem to work but they are difficult to replicate. What we still 
need are pragmatic lifestyle interventions that can delay the onset of diabetes. We need to decide whether we want to spend more on drugs for prevention rather than on lifestyle measures and public health strategies to reduce the burden of chronic disease.

Carl Heneghan deputy director

(carl.heneghan@dphpc.ox.ac.uk)

M Thompson clinical lecturer

$\mathrm{R}$ Perera senior statistician

Centre for Evidence Based Medicine, Department of Primary Health Care, University of Oxford, Oxford OX3 7LF

Competing interests: None declared.

1 King H, Aubert RE, Herman WH. Global burden of diabetes, 1995-2025: prevalence, numerical estimates, and projections. Diabetes Car prevalence, num

2 Harris MI, Eastman RC. Early detection of undiagnosed diabetes mellitus: a US perspective. Diabetes Metab Res Rev 2001;16:230-6.

3 Diabetes Prevention Program Research Group. Reduction in the incidence of type 2 diabetes with lifestyle intervention or metformin. $N$ Engl J Med 2002;346:393-403.
4 Tuomilehto J, Lindstrom J, Eriksson JG, Valle TT, Hamalainen H, IlanneParikka P, et al; Finnish Diabetes Prevention Study Group. Prevention of type 2 diabetes mellitus by changes in lifestyle among subjects with impaired glucose tolerance. N Engl J Med 2001;344:1343-50.

5 Nesto RW, Bell D, Bonow RO, Fonseca V, Grundy SM, Horton ES, et al. Thiazolidinedione use, fluid retention, and congestive heart failure: a consensus statement from the American Heart Association and American Diabetes Association. Diabetes Care 2004;27:256-63.

6 Torgerson JS, Hauptaum J, Boldrin MN, Sjostrom L. XENical in the prevention of diabetes in obese subjects (XENDOS) study: a randomized study of orlistat as an adjunct to lifestyle changes for the prevention of type 2 diabetes in obese patients. Diabetes Care 2004;27:155-61.

7 DREAM (diabetes reduction assessment with ramipril and rosiglitazone medication) Trial Investigators; Gerstein HC, Yusuf S, Bosch J, Pogue J Sheridan P, Dinccag N, et al. Effect of rosiglitazone on the frequency Sheridan P, Dinccag N, et al. Effect of rosiglitazone on the frequency
of diabetes in patients with impaired glucose tolerance or impaired fasting glucose: a randomised controlled trial. Lancet 2006;368: 1096-105.

8 Anonymous. Effect of ramipril on the incidence of diabetes. $N$ Engl J Med 2006 Sep 15 [Epub ahead of print].

9 Montori VM, Busse JW, Permanyer-Miralda G, Ferreira I, Guyatt GH. How should clinicians interpret results reflecting the effect of an intervention on composite endpoints: should I dump this lump? ACP J Club 2005;143:A8.

doi 10.1136/bmj.38996.709340.BE

\section{$\mathrm{X}$ ray imaging goes digital}

\section{Digital imaging brings benefits but also demands changes in ways of working}

$\mathrm{D}$ igital $\mathrm{x}$ ray imaging has brought obvious benefits to health care, but, as with all new technologies, it both requires and leads to changes in behaviour and processes, some obvious and some less so. The issues include cost and productivity, the need to acquire new skills, radiation doses, overuse, and image quality. Moreover, some of the ethical and legal issues surrounding teleradiology remain unclear. ${ }^{1}$

Physicians have long been accustomed to viewing and interpreting images on film. Film is now being replaced with digital images in the same way as film cameras are being replaced with digital cameras. Digital $\mathrm{x}$ ray imaging does away with film processing, and the images can be viewed just minutes after exposure via computer networks, to be seen by many people at once, in many different places. So what are the issues surrounding the transition to digital imaging?

The initial cost of buying digital systems has dropped substantially during the past two decades, but such systems are still more expensive than a conventional system. Conventional film images can be viewed anywhere, just by holding up the film to light, whereas monitors with network connections and software capabilities are needed to view digital images. The high cost of implementation has clearly impeded the adoption of digital systems, though some cost analyses have shown that the high cost can be justified in a high volume setting. ${ }^{23}$ The increase in the overall speed of service, from the request for an examination to reporting, may also justify the high cost. One comparison of the operating and investment costs of conventional and digital systems found that the average total cost of digital technology was $20 \%$ lower than that of a conventional system. ${ }^{3}$ Several studies have shown that the transition to filmless technologies offers potential for improved workflow and increased productivity. ${ }^{2} \mathrm{w}$

New technology requires new skills. Physicians must become familiar with viewing images on a display images not as acceptable as film for interpretation. ${ }^{4}$ Today, high resolution displays have greatly aided interpretation of digital images.

It was once thought that digital systems would reduce radiation doses. They can facilitate dose monitoring by recording factors that have direct bearing on radiation exposure to patients, such as $\mathrm{x}$ ray tube voltage and tube current. Any technical errors can be promptly rectified, thus further reducing risk to the patient. Although some studies have shown dose reductions, ${ }^{5}$ w2 there is a tendency towards increased doses. ${ }^{6}$ The reasons include the fact that overexposure can go undetected, unlike with film, where the image turns dark, but more important factors are a tendency to take more images than necessary and at a higher image quality (and hence radiation dose) than necessary.

One study showed that some centres with digital systems used an average of 68 exposures per examination in upper gastrointestinal fluoroscopic examinations, compared with 16 exposures in other centres with conventional systems. ${ }^{7}$ In several US hospitals the number of examinations per inpatient day increased by $82 \%$ after transition to digital systems and the number of examinations per outpatient visit increased by $21 \%$, while the number of examinations per visit nationally decreased by $19 \% .{ }^{8}$ It is easy to delete digital images, and repeat exposures normally go undetected.

Different imaging tasks require different levels of image quality. For example, the follow-up examination for a fracture does not require the same image quality as that required for its diagnosis. ${ }^{8}$ w3 A lower quality image may look slightly less clear but still be good enough for diagnosis. The image quality routinely used in digital imaging is often greater than that required for diagnosis, so how does a physician know if it is higher than necessary? This is a question of training.

Extra references w1-w4 are on bmj.com 